\title{
La adaptación de la Administración española a la Unión Europea: un proceso de evolución y aprendizaje permanente
}

Eduardo Zapico Goñi *

\section{Introducción: importancia y dificultad de la adaptación administrativa}

Uno de los desafíos con que se encuentra la Unión Europea (UE) menos estudiados es el desequilibrio existente entre la capacidad de gestión y los objetivos de integración ratificados en el Tratado de Maastricht. Aunque este déficit de gestión se identifica en ocasiones con lo limitado de las competencias y dimensión de la Comisión Europea lo cierto es que "... la integración regional no es posible sin el apoyo de elites claves del sector privado, de la academia y de poderosas burocracias nacionales. La integración regional (Europea) no puede tener éxito sin un grado suficiente de capacidad de gestión tanto a nivel nacional como supranacional" (P. SMITH, 1993). La viabilidad del proyecto europeo está condicionada a que se diseñe y desarrolle una colaboración estrecha entre múltiples organizaciones públicas y privadas situadas a distintos niveles de gobierno (COMISIÓN EuRopea, 1994: 8; Milward, 1992: 3). El desartollo de la UE depende de la capacidad de gestión de múltiples relaciones interorganizacionales. Requiere el establecimiento, desarrollo y consolidación de un tejido relacional y funcional eficaz entre los distintos niveles de gobierno y dentro de cada uno de ellos, y entre éstos y el sector privado. La eficacia final de los procesos de decisión y puesta en práctica de las políticas de la UE dependen en gran medida de la capacidad de gestión de las interacciones y negociaciones inter e intra gubernamentales. Sin embargo, la adaptación de las Administraciones de los Estados Miembros (EM) a la creciente internacionalización de los problemas y políticas europeas más allá de la esfera doméstica o diplomática tradicional ha sido hasta ahora la cenicienta de los programas de reforma del sector público. Mejorar la capacidad nacional de gestión de las negociaciones europeas es un paso necesario e inevitable en la construcción europea (MetcalfE, 1994: 271; KLIKSBERG, 1994: 189, 190).
La dificultad de mejorar la participación de las Administraciones nacionales en la toma de decisiones europeas es mayor de lo que suele pensarse. La formulación de la política europea es el resultado de un proceso de múltiples interacciones negociadas entre representantes de los EM caracterizadas por los siguientes factores de complejidad (WALTON y MCKERSIE, 1965: 133):

- Se superponen componentes técnicos y humanos. Los valores, actitudes, sentimientos, percepciones sobre penalizaciones y recompensas, etc., de los participantes afectan tanto o más que los aspectos técnicos en los resultados de las negociaciones y, en definitiva, en la eficacia del proceso decisorio. Esto es especialmente importante dada la siguiente característica.

- Los acuerdos negociados se prolongan en el tiempo. La naturaleza continuada de las negociaciones es evidente. Hay nuevas negociaciones post-acuerdo por revisión o reinterpretación de los acuerdos durante la fase de implementación. Además, el proceso de decisión es una serie sucesiva de negociaciones concatenadas en el tiempo. Los temas de negociación pueden cambiar pero los negociadores suelen mantenerse.

- Es difícil identificar y compatibilizar los intereses nacionales con los intereses europeos. No suele haber una comparación fácil ni precisa sobre los beneficios de defender los intereses individuales (nacionales) o los de grupo (europeos).

- Los negociadores que participan directamente en las negociaciones europeas representan directa $u$ indirectamente a organizaciones (departamentos ministeriales, otros niveles de gobierno, intereses privados, etc.) cuyos miembros influyen en su comportamiento negociador ejerciendo múltiples presiones a menudo incompatibles.

Esta última fuente de complejidad es particularmente importante en las negociaciones europeas y es el centro de interés de este artículo. Los esfuerzos de negociación realizados en Bruselas son tan sólo la fase final del proceso decisorio. Aunque los 
actores principales se identifican claramente en la figura de los representantes de los gobiernos nacionales sería irrealista suponer que éstos defienden posturas neutras de negociación, puramente técnicas, formal y plenamente aceptadas mediante un proceso de formulación automática en cada capital de origen. La definición del interés nacional no es algo evidente en sí mismo. La postura que los representantes de cada país tomen en Bruselas exige y depende de un contacto estrecho entre múltiples centros de decisión, coordinación y participación (pública y privada) a todos los niveles de gobierno. La eficacia de la estrategia de negociación seguida por un Estado Miembro depende de un esfuerzo prolongado e intenso de preparación que permita integrar los diversos intereses internos.

La adaptación de España a la UE no es sólo una cuestión de transposición de leyes sino además de una reorganización en su Administración que garantice su participación eficaz en el proceso de toma de decisiones europeas. Esto significa la participación en una serie de incansables negociaciones en múltiples comités de expertos en la Comisión Europea y en los grupos de trabajo del Consejo, en el COREPER y en el Consejo de Ministros. Los beneficios que España pueda obtener del desarrollo de la Unión Europea dependen en gran medida de cómo los delegados españoles negocian y consiguen apoyo para las posiciones españolas. Está claro que su experiencia profesional y habilidad negociadora son determinantes en este sentido. Pero además el papel jugado por los delegados españoles en Bruselas está también muy influido por la calidad de las instrucciones recibidas de Madrid. La calidad de estas instrucciones depende de un proceso largo de coordinación previo y/o simultáneo al propio proceso de negociación en Bruselas con el fin de integrar los distintos intereses de los centros y grupos afectados por las decisiones europeas. La eficacia de los delegados españoles depende de la capacidad del gobierno y las Administraciones públicas para agregar todos los intereses internos y formular una postura común.

Según un alto cargo del Ministerio de Asuntos Exteriores, "el riesgo de quiebra del principio de unidad de acción exterior es considerabie en el plano multilateral". Cada Ministerio tiende a conectar directamente con su organización internacional especializada correspondiente. Esto explica que a veces el Ministerio de Economía y Hacienda desarrolle una política en la OCDE, Trabajo otra en la OIT, Salud otra en la OMS, Educación otra en la UNESCO, Agricultura otra en la FAO, etc... (VillaR, 1985, pág. 122). Peor aún sería que en una misma organización internacional los distintos ministerios involucrados tendieran a desarrollar políticas de actuación incompatibles.

La preparación interna de las posiciones de negociación de cada Estado Miembro para participar en la toma de decisiones europeas tiene una doble proyección. No sólo asegura la coherencia global de los intereses del Estado Miembro, sino que ade- más facilita el funcionamiento apropiado del proceso decisorio a nivel europeo. La debilidad de los mecanismos de coordinación nacional, previos a las negociaciones europeas, puede provocar un perjuicio a los intereses nacionales y al funcionamiento global de la UE, tanto en la fase de formulación como en la de implementación y desarrollo de sus políticas (SIEDENTOPF, ZILLER, 1988: 5). En la medida en que no se coordinen adecuadamente los intereses nacionales previamente a las negociaciones europeas lo más probable es que durante la implantación de los programas europeos surjan dificultades para su puesta en práctica. Si la postura defendida por un delegado en las negociaciones europeas no representa o sintetiza los intereses de los grupos o agencias que posteriormente van a ser responsables de la ejecución de las decisiones, surgirán tensiones y conflictos y se debilitará la eficacia final de las políticas.

La falta de adaptación de la Administración de un Estado Miembro a la toma de decisiones a nivel europeo no sólo puede dar pie a acuerdos que vayan en contra de los propios intereses nacionales sino que además puede estar bloqueando el proceso decisorio de integración europea. La coherencia en los sucesivos planteamientos de negociación de un Estado Miembro a lo largo del tiempo es fundamental no sólo para su credibilidad ante los demás Estados sino además para el buen funcionamiento y eficacia de las decisiones europeas. La estabilidad en los planteamientos defendidos por un país y la coherencia en las posturas de sus distintos representantes según las políticas sectoriales de que se trate son esenciales en este sentido. En caso contrario, el nivel de conflictos podría dispararse bloqueando sustancialmente el proceso decisorio a nivel europeo.

La dificultad de integrar estos intereses se acentúa con el desarrollo del proyecto europeo. La mayor profundidad deepening de las políticas de la UE va difuminando los límites entre política exterior y política interior. Los ministerios de Asuntos Exteriores y los departamentos de Comercio Exterior no son los únicos competentes ni disponen de recursos suficientes para representar a un Estado Miembro en las múltiples políticas europeas. Cada vez son menos las decisiones que pueden ser eficazmente preparadas por un departamento de manera aislada, cada vez es mayor el número de actores y sectores interdependientes. En este contexto resulta imprescindible estudiar la capacidad de coordinación disponible y necesaria para participar con eficacia en las negociaciones europeas.

En definitiva, la capacidad de coordinación es un componente fundamental de la adaptación nacional al proceso de negociaciones de la integración europea. En este trabajo se presenta, en primer lugar, un concepto de coordinación y un instrumento de medición de la capacidad de coordinación interministerial existente en una Administración para preparar posturas de negociación europeas. Posteriormente, se describen y analizan las funciones y las relaciones entre los principa- 
les participantes de la Administración Española, incluidas las Comunidades Autónomas, en los procesos de coordinación previos a la toma de postura de los negociadores españoles en Bruselas. Finalmente y de manera tentativa se analizará la evolución de la eficacia del sistema de coordinación en la Administración Española evaluándolo en base al marco teórico, instrumento de medición antes referido.

Dado que España ingresó en la Comunidad en 1986 es lógico esperar que su sistema de coordinación ha estado experimentando un rápido desarrollo, siendo importante que se tenga en cuenta las posibles variaciones a lo largo del tiempo. Por lo tanto, este estudio es una comparación longitudinal de la variación del nivel de coordinación de la Administración española. De hecho el esfuerzo de coordinación y adaptación administrativa tuvo que empezar antes de la propia integración en la Comunidad. Por lo tanto, en sus respectivas secciones se pretende analizar el funcionamiento de los sistemas de coordinación antes y después de la integración teniendo en cuenta los últimos cambios acaecidos tras la presidencia del Consejo que ha correspondido a España en el segundo semestre de 1995. La intención es presentar una síntesis de cómo el sistema funcionaba antes del acceso a la Comunidad, analizar el sistema de coordinación tras el acceso a la Comunidad y, finalmente, interpretar la evolución que va produciéndose a lo largo de los últimos años incluyendo el de su segunda presidencia.

\section{Capacidad de coordinación: concepto} y medida

Hemos visto que la definición del interés nacional no es algo evidente en sí mismo, ni automático. La eficacia de la postura que los representantes permanentes y los delegados de cada país tomen en las negociaciones europeas exige y depende de que exista un estrecho contacto entre los centros de decisión y coordinación. Las opiniones de los distintos ministerios y grupos de interés afectados por las negociaciones europeas tienen que ser de alguna manera tenidas en cuenta. Las negociaciones europeas exigen un esfuerzo de coordinación nacional previo al debate en los encuentros con los delegados de otros países. Este estudio se centra en el esfuerzo de coordinación previo a la toma de decisiones, durante lo que se suele llamar fase ascendente.

La evaluación de la capacidad de coordinación nacional para su participación en el proceso de elaboración de la política europea requiere, en primer lugar, la elección de un marco teórico que permita la definición y medida del propio concepto de coordinación. La coordinación en general significa la interrela- ción de las partes de un sistema para conseguir un objetivo o su buen funcionamiento. Pero esta definición no es lo suficientemente operativa como para permitir su medición y realizar el seguimiento de su evolución. En una Administración burocrática tradicional se asocia el concepto de coordinación con el de control jerárquico. A menudo también se entiende la coordinación como un derecho a ser formalmente informado o la obligación de aceptar unos objetivos impuestos desde arriba. Sin embargo, la coordinación es un atributo de un sistema no una prerrogativa de un sujeto o unidad de coordinación.

Uno de los factores más influyentes en la coordinación de un sistema es la cultura o valores de comportamiento del personal. En paises con funcionarios que se identifican con valores burocráticos, la coordinación se percibe como una responsabilidad de la unidad central. La actitud del personal es más bien reactiva. No se reconoce la corresponsabilidad activa y voluntaria como un factor fundamental para que funcionen los mecanismos de coordinación. Se suele escuchar la queja del personal reflejando una actitud pasiva con respecto a la coordinación, "nadie me ha informado ...". Por lo tanto, un aspecto fundamental del sistema de coordinación para las negociaciones europeas es el pasar de una cultura interorganizacional reactiva a una cultura más activa y voluntaria en el modus operandi de la coordinación. El cambio de una actitud pasiva a otra más activa, en la búsqueda de información y de puesta en marcha de los procesos de consulta, etc., es un paso esencial para mejorar la eficacia de los sistemas de coordinación. Cuanto antes se obtenga información respecto a las iniciativas de propuestas legislativas y proyectos de directivas en la Comisión Europea, más tiempo habrá para reaccionar con eficacia en la preparación de las posturas nacionales.

En una investigación llevada a cabo a finales de los 80 en el Instituto Europeo de Administración Pública (IEAP), se comparó el grado de coordinación interministerial alcanzado por los sistemas administrativos de los entonces 12 Estados miembros de la CE. Con el fin de medir la capacidad de coordinación se utilizó la escala de coordinación de Les Metcalfe (1994). Esta escala permite llevar a cabo una medición cualitativa y sistemática de la coordinación. La escala tecoge los componentes más o menos ya conocidos de coordinación, pero además los ordena de manera sistemática. Figuradamente no es sino una escalera o serie de escalones. Cada uno de estos escalones representa por orden creciente un nivel más elevado de coordinación. Una caracteristica importante de esta escala de medida, que es del tipo Guttman, es su naturaleza acumulativa. La posición en un escalón indica no sólo el cumplimiento de las exigencias de ese nivel de coordinación, sino además el de los escalones inferiores.

La escala de coordinación (véase cuadro de la página siguiente) de la formulación de la política europea supone la ordenación de menor a mayor del nivel de coordinación alcanzado en 
la formulación de la posición que un Estado Miembro defiende en las negociaciones europeas. La idea básica es que en cada escalón se representa una mayor capacidad de coordinación y que para pasar de un nivel al siguiente hay que consolidarlo antes. Los sucesivos niveles de coordinación se refieren en este caso a las relaciones interministeriales. Veamos el significado de cada nivel de la escala empezando por el nivel inferior de coordinación (Les METCALFE, 1994):

\section{ESCALA DE COORDINACION *}

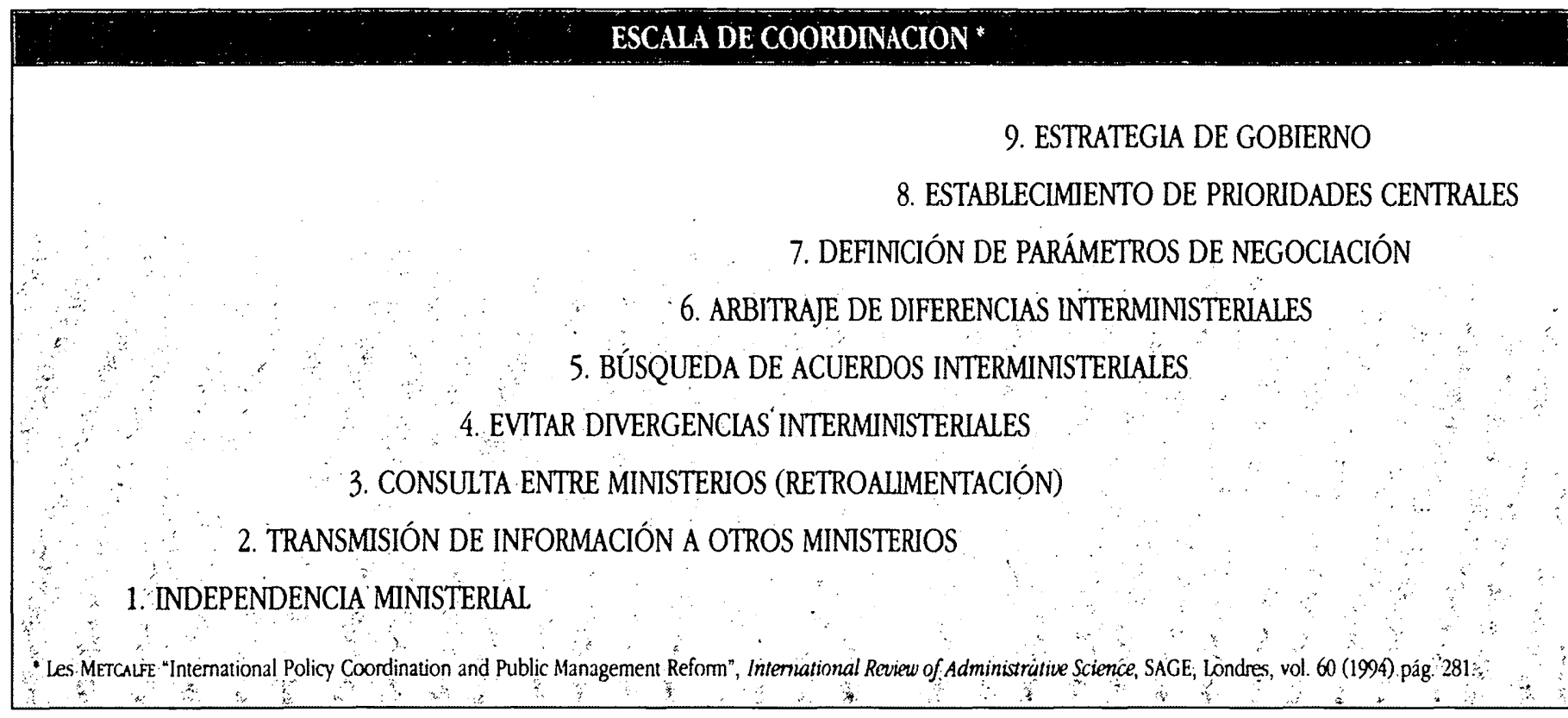

\section{NIVELES DE IA ESCALA DE COORDINACIÓN}

\section{Independencia ministerial}

Cada departamento formula individualmente su postura de negociación sin prestar atención a lo que otros departamentos están haciendo. La autonomía es plena. Pero este nivel no representa un nivel cero de coordinación. Para consolidar este nivel de coordinación es necesario haber realizado un reparto claro de responsabilidades y tareas de cada departamento. La red de organizaciones/centros que participan en el proceso de integración europea debe estar bien identificada y diseñada. El reparto de competencias debe ser conocido y estar aceptado por todos. Se evitan duplicidades innecesarias. Además, cada departamento debe tener capacidad para actuar (recursos) en función de sus competencias

\section{Transmisión de información a otros Ministerios}

El intercambio de información es una condición necesaria para iniciar una mejora en la coordinación. En este nivel, aunque los departamentos conservan su autonomía de decisión, se supone que existe la obligación de informar, y de hecho se informa, a otros departamentos de la política que se está siguiendo. Existen normas o convenciones para que se informe a otros departamentos. Existen canales y procedimientos, formales o informales, pero regulares de comunicación. Los sistemas de información funcionan con eficacia. La información enviada es útil, relevante y oportuna.

\section{Consulta entre Ministerios (Retroalimentación)}

La transmisión de información va seguida de una reacción por parte del departamento receptor. El flujo de información se da en los dos sentidos. Cada departamento, además de informar sobre lo que está haciendo, recibe una respuesta valorativa de otros respecto a su propia política. Se acepta la influencia de otros pero cada departamento se sigue sintiendo no condicionado (autónomo) respecto a los demás. La información se considera fiable y es aceptada, atendida a tiempo y bien tratada en el departamento consultado. Una evidencia clara de que se cumple este nivel de coordinación sería el que las instrucciones de negociación van complementadas o reforzadas con comentarios de terceras partes. Pero los departamentos que iniciaron la consulta pueden o no utilizar las respuestas recibidas. Siguen planteando las negociaciones de manera autónoma

\section{Evitar divergencias interministeriales}

La Administración intenta hablar con una sola voz en las negociaciones europeas. Hay estructuras y procedimientos, formales o informales, pero regulares que permiten influir directa $o$ indirectamente en el comportamiento de otros departamentos. Se desarrollan mecanismos para evitar divergencias o incoherencias manifiestas. Los departamentos intentan evitar situaciones en las que se sigan públicamente líneas inconsistentes o contradictorias en las negociaciones europeas, mediante un con- 
tacto y discusión directa después de definir sus posiciones. Se trata de una interacción para evitar conflictos abiertos y ocultar desacuerdos antes de crear compromisos frente a terceros (coordinación negativa). No revelar conflictos internos, lavar la ropa en casa. Existen resistencias ocultas a otros departamentos. Una evidencia clara de que se funciona a este nivel de coordinación podría ser la existencia de un alto porcentaje de instrucciones de emergencia.

\section{Büsqueda de acuerdos interministeriales}

En lugar de una coordinación "negativa" orientada a la prevención de que las contradicciones sean públicas, los departamentos trabajan conjuntamente de manera más positiva para alcanzar posturas más coherentes y/o complementarias. Este nivel de coordinación exige un mayor esfuerzo y anticipación. No se trata sólo de solucionar conflictos ya existentes sino de buscar intereses comunes. Se reconoce y acepta la interdependencia e interés mutuo. Existe una interacción positiva que permite intercambiar información con el fin de identificar oportunidades o intereses comunes, políticas complementarias, objetivos comunes, etc. Se confrontan las incertidumbres y diferencias con otros departamentos para definir la propia postura de negociación. Si hay resistencias, éstas son abiertas. No hay un alto porcentaje de instrucciones de emergencia.

\section{Arbitraje de diferencias interministeriales}

Cuando las contradicciones no pueden ser resueltas mediante el proceso de coordinación voluntario, de abajo arriba, hasta ahora descrito, se impone la necesidad de implantar un sistema de arbitraje. Se necesita una unidad central para la solución de los conflictos. Un centro coordinador o autoridad "externa" resuelve obligatoriamente los conflictos. El rol de la unidad central se debe realizar teniendo en cuenta las opiniones de todos los afectados y con consciencia de los problemas de los departamentos. La unidad central debe funcionar con legitimidad y credibilidad. Además, debe de tener capacidad (recursos) para confrontar con eficacia los conflictos que se le plantean.

\section{Definición de parámetros de negociación}

El centro coordinador realiza un papel más activo, fijando unos límites o parámetros de referencia (i.e. limitaciones presupuestarias) ante la discreción de los departamentos. Estos límites pueden dejar un margen amplio de decisión a los departamentos dentro de un marco o política de restricciones de recursos, consecuencias financieras u otros parámetros en la configuración de su política. Se define lo que los ministerios no pueden hacer (coordinación negativa). Se establecen criterios que permiten a los departamentos identificar posturas no deseadas. Se penalizan decisiones o comportamientos no coherentes con acción gubernamental o colectiva.

\section{Establecimiento de prioridades centrales}

La definición de prioridades ofrece una línea de acción 0 dirección de trabajo para los Ministerios. El conjunto de las prioridades elegidas ofrece un marco claro de referencia y expectativas sobre la manera en que deben ser resueltas las diferencias interdepartamentales. Las prioridades comunes proporcionan un marco coherente para la formulación de políticas de cada Ministerio. La unidad central define unas líneas o políticas claves de actuación, prioridades, en colaboración con los departamentos participantes requiriendo un análisis en profundidad de la situación. No se trata sólo de formular un programa del partido o definir la misión general. El papel de la unidad central es más de orientación y apoyo. Proporciona una visión global. Una evidencia clara de coordinación a este nivel es el que se incentivan y recompensan las decisiones coherentes con los intereses gubernamentales o colectivos enviando señales positivas de reconocimiento. Su puesta en práctica efectiva depende de que funcionen los niveles inferiores

\section{Estrategia de gobierno}

Este es un caso límite. El Gobierno actúa como un todo plenamente unificado en la formulación y desarrollo de una política global incuestionable. Este nivel supone que los departamentos son meros instrumentos mecánicos que elaboran e implementan automáticamente su estrategia basándose en una información plena y unos objetivos perfectamente definidos. El Gobierno puede diseñar su estrategia perfectamente pero la formulación de las políticas sectoriales y estrategia finalmente aplicada de negociación depende de un buen funcionamiento interdepartamental. Este nivel se incluye para completar la escala más que por ser alcanzable. Exige una plena confianza mutua entre el Gobierno, la unidad central de coordinación y los departamentos que aceptan y aplican de manera incuestionable los objetivos y la estrategia gubernamental.

Existe una clara interdependencia entre los niveles de la escala. Por su naturaleza acumulativa sabemos que para alcanzar apropiadamente un nivel hay que consolidar los niveles inferiores. Por el hecho de tener unas prioridades no puede decirse que se alcance el nivel 8 si no funcionan bien los sistemas de información. De la misma manera puede decirse que en la medida que los niveles superiores estén mejor definidos se facilitará la consolidación de los niveles inferiores o voluntarios. En este caso, los mecanismos voluntarios de coordinación pueden anticipar cuál va a ser el criterio a aplicar en los sistemas de arbitraje. Muchos de los conflictos se resolverán voluntariamente al anticiparse la decisión jerárquica más probable.

La escala no lleva implícito un juicio de valor. No enjuicia ni explica, sólo mide el nivel de coordinación máximo alcanzable. No puede decirse que cuanto más coordinación mejor siempre. 
Puede haber temas o políticas que requieran la actuación de un solo Ministerio, siendo el nivel 1 de coordinación suficiente. La coordinación no es gratuita, tiene un coste. La utilidad de la escala es que permite comparar el nivel real de coordinación con el nivel deseable o necesario. La metáfora del termómetro y la medición de la temperatura de los animales es un ejemplo muy ilustrativo para explicar la utilidad de la escala. El termómetro nos permite medir la temperatura de un animal y compararla con su estado ideal. Sin embargo, no sirve por sí sola para explicar las diferencias que puedan identificarse entre distintos animales. No puede decirse que a mayor temperatura mejor siempre. El nivel de coordinación deseable depende de qué política u organización se trate. La escala sirve para comparar la coordinación ideal o necesaria con la coordinación real. La capacidad de coordinación debe ser acorde con la complejidad a tratar. Cuanto mayor es la interdependencia entre temas o políticas europeas mayor será la necesidad de disponer de más capacidad de coordinación.

Con la utilización de la escala se pretende en este trabajo medir la capacidad general que como máximo puede poner en funcionamiento la Administración Española a la hora de preparar las negociaciones europeas. Los niveles que se están comparando, por lo tanto, no hacen referencia a una política concreta o sector específico, sino a cómo va evolucionando la capacidad máxima de coordinación global.

\section{La coordinación de la política europea en España}

3.1 Breve referencia bistórica: flexibilidad en las negociaciones para la adbesión europea

El esfuerzo de coordinación fue necesario desde el comienzo del período de consultas y negociaciones bilaterales entre la Comunidad y España para la integración. Tras la solicitud de integración en la Comunidad realizada por la Administración española el 28 de julio de 1977, se nombró a un Ministro sin cartera para las Relaciones con las Comunidades Europeas. En marzo de 1981 este Ministerio desaparecía y el Ministerio de Asuntos Exteriores absorbía sus competencias. De hecho, sus servicios se agruparon bajo la Secretaría de Estado para las Relaciones con las Comunidades Europeas que jugaba el mismo papel que el Ministerio antes mencionado. En octubre de 1982, el partido socialista tras ganar las elecciones afirmó su inclinación europea y su intención de proporcionar un apoyo pleno para completar la integración. El proceso de negociaciones se aceleró y el 19 de marzo de 1985 se alcanzó un primer acuerdo económico y político. El Tratado de adhesión se firmó el 12 de junio de 1985. Desde junio de 1985 hasta enero de 1986, duran- te el período interino, los delegados españoles se incorporaron gradualmente a las instituciones comunitarias y tomaron parte en el proceso de toma de decisiones sin tener aún derecho a voto.

En agosto y septiembre de 1985 se crearon nuevas unidades administrativas adaptadas para sustituir a las que hasta entonces se habían encargado de las negociaciones con la Comunidad. Durante las negociaciones previas a la integración, el proceso de integración era responsabilidad de la Secretaría de Estado para las Relaciones con las Comunidades Europeas, y el Consejo de Coordinación de las Relaciones con las Comunidades Europeas. Este Consejo, en el que estaban representados los ministerios de las distintas políticas sectoriales, se reunía al menos una vez al mes. Con el fin de asegurar la continuidad de su papel, delegó los trabajos previos en la llamada Task Force. El presidente de esta Task Force tenía el status de subsecretario y sus miembros representaban al Ministerio de Economía y Hacienda, Agricultura, Industria, Trabajo y Seguridad Social, la Secretaría de Estado para Relaciones con las Comunidades Europeas y Presidencia de Gobierno.

De hecho, la coordinación durante el proceso de negociación para la integración era responsabilidad de un grupo pequenoo de altos funcionarios que trabajaban a través de contactos continuados no muy formalizados, en el marco de la Task Force (niveles voluntarios de coordinación 4 y 5). Las decisiones se tomaban por consenso. Y en caso de desacuerdo la Presidencia de Gobierno tenía la última palabra, (nivel 6 de coordinación).

Durante este proceso se hizo un importante esfuerzo para asegurar la participación de las Comunidades Autónomas a través del llamado Plan de Acción Interior que supuso alrededor de 500 reuniones con Comunidades Autónomas y con organizaciones empresariales y sindicatos (niveles 2 y 3 de coordinación). El plan no era rígido ni estaba formalmente institucionalizado. Las reuniones se realizaban de manera ad boc y con flexibilidad. Según las opiniones de los funcionarios entrevistados "el sistema de coordinación administrativa en España era rápido, flexible y eficaz". Esto era principalmente debido a tres importantes factores: 1. El tipo informal de discusiones entre los miembros de la Task Force y con terceros; 2 . El fuerte apoyo político disfrutado por el Secretario de Estado para las Relaciones con las Comunidades Europeas en aquel momento; y 3. La indiscutible prioridad de conseguir la integración. El nivel alcanzado en la escala de coordinación fue muy elevado en torno al nivel 8 . Veamos a continuación la evolución del sistema después de la adhesión.

3.2 La coordinación de la politica europea tras la adhesión: un proceso oficial de coordinación largo y centralizado

La integración de España en la Comunidad Europea significó la necesidad de un reforzamiento de la coordinación interministerial. Desde el 1 de enero de 1986, fecha de la integración, 
España se vio incorporada a un proceso de negociaciones mucho más complejo. Estas negociaciones incluían un mayor número de temas que antes de la adhesión y, además, estos temas tenian que negociarse en un marco multilateral no bilateral como ocurria antes de la adhesión. Los delegados españoles participaban en la formulación de todas las directivas y regulaciones comunitarias, no negociaban solamente los temas que afectaban a España. Además tenían que defender las posiciones españolas multilateralmente frente a todos y cada uno de los miembros de la Comunidad simultánea e individualmente más que frente a todos ellos como grupo bilateralmente.

Con el fin de reaccionar a este nuevo reto el gobierno espanool reestructuró la red de coordinación administrativa. Se crearon nuevas unidades centrales de coordinación, la Secretaría de Estado para las Comunidades Europeas (SECE) y la Comisión Interministerial para Asuntos Económicos relacionados con la Comunidad Europea (CIAECE). Además, tanto la SECE como la Representación Permanente vieron reforzados sus servicios con más personal y un equipamiento más moderno.

Desde la adhesión hubo una tendencia a aumentar la formalización y centralización del proceso de coordinación y transmisión de instrucciones. El sistema español se desarrolló desde el principio en base a un modelo centralizado con elementos comunes al sistema francés e inglés, intentando incluso introducir algunos elementos del modelo alemán dadas las especiales características regionales de ambos países.
El proceso oficial de coordinación es largo y muy formalizado. Toda la información debe fluir desde la Representación Permanente hacia los Ministerios gestores a través de la SECE, perteneciente al Ministerio de Asuntos Exteriores. Tras recibir la información, la SECE la envía a las Secretarías Generales Técnicas de los Ministerios gestores. Esta unidad es la encargada de distribuir la información entre las Direcciones Generales y organismos implicados. Posteriormente y con cierta periodicidad, la Comisión Interministerial (CIAECE), es convocada por la Secretaría de Estado para las Comunidades Europeas con el fin de estudiar y resolver los asuntos que afectan a más de un departamento. Si algún asunto o tema es considerado políticamente relevante o si alguno de los miembros de la Comisión Interministerial lo requiere, la decisión es trasladada a la Comisión Delegada del Gobierno para Asuntos Económicos (CDGAE), con la participación del Ministerio de Asuntos Exteriores y el Secretario de Estado para la Comunidad Europea para resolver el conflicto y establecer la posición prioritaria de España ante Europa. Si el desacuerdo persiste el Consejo de Ministros tiene la última palabra. La decisión última se convierte en una instrucción comunicada a la Representación Permanente a través de la Secretaría de Estado para las Comunidades Europeas (ver figura 1). El nivel de coordinación que se consideraba necesario, al que aspiraba el modelo oficial, estaría como mínimo situado entre el nivel 7 u 8 de la escala.

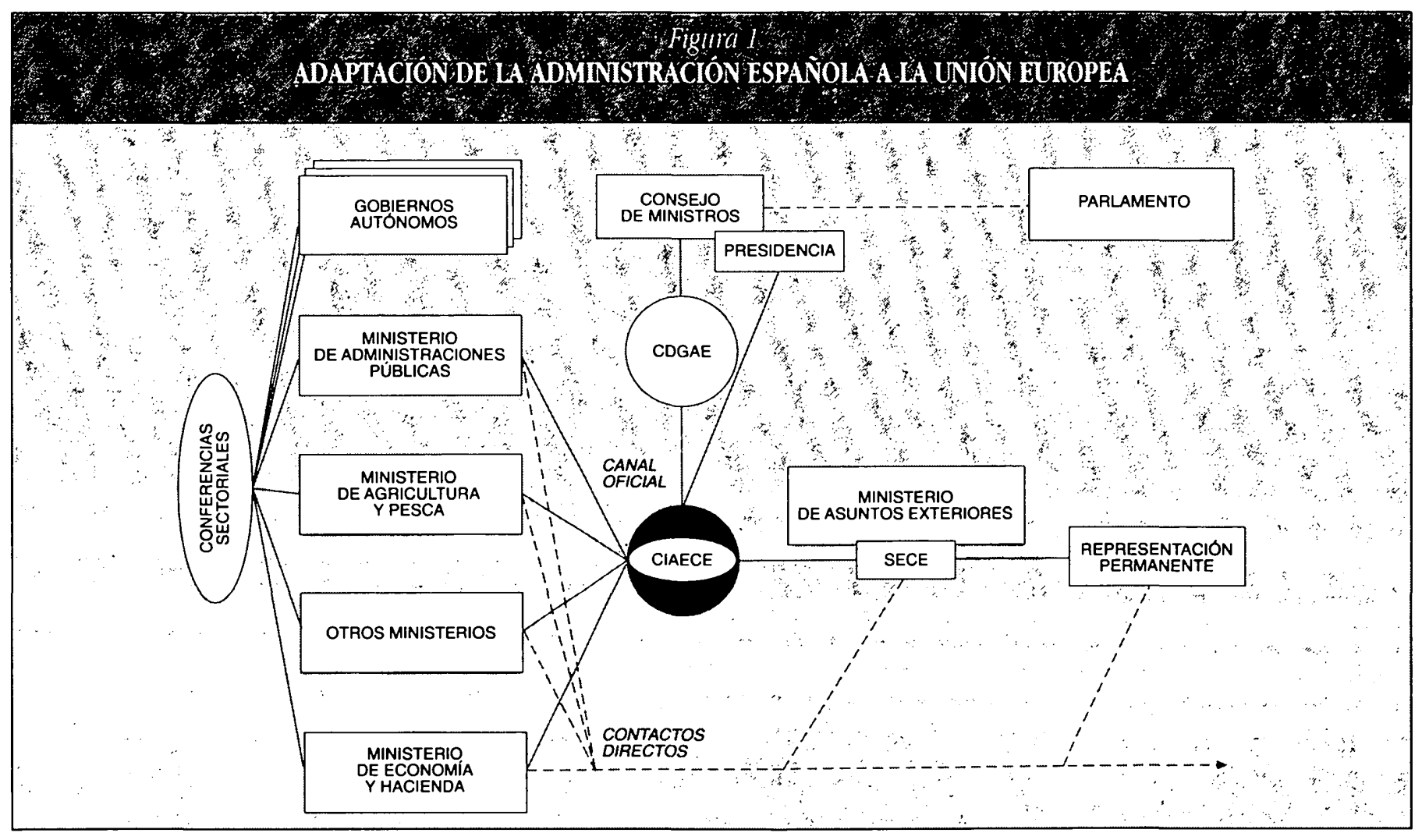


A continuación se analizan las funciones de los principales órganos encargados de definir la postura española y los canales utilizados para integrar las distintas opiniones e intereses de los principales participantes en este proceso, el rol que juegan y el grado de coordinación con que funciona el sistema en su conjunto.

3.2.1 La Secretaría de Estado para las Comunidades Europeas (SECE).

A finales de agosto de 1985 la unidad central de coordinación para temas comunitarios adaptó su estructura y competencias para responder al ingreso en la Comunidad. Esta adaptación se presentó oficialmente como un "cambio fundamental para convertir esta unidad en un instrumento apropiado para la coordinación de la acción de la Administración española en las instituciones comunitarias", así como "una consecuencia de su transformación de unidad de negociación en unidad de gestión" ". La SECE se creó como responsable de la coordinación administrativa y de la formulación y ejecución de la política comunitaria española. Con el fin de jugar un papel principal en la coordinación de la Administración, la Secretaría de Estado se estructura en dos divisiones: la Dirección General de Coordinación Técnica y la Dirección General de Coordinación Institucional y Legal. La primera se estructura por temas y políticas sectoriales y se divide en cuatro subdirecciones, cada una de ellas agrupando sectores más o menos homogéneos:

1. Agricultura y Pesca;

2. Asuntos económicos, financieros y sociales;

3. Comercio y Aduanas;

4. Industria, Energía, Transporte y Comunicaciones

Los Directores generales y otros funcionarios de nivel jerárquico inferior son los responsables de presidir grupos de trabajo de nivel técnico dentro de la Secretaría de Estado para las Comunidades Europeas. Los participantes de estos grupos son representantes al nivel técnico correspondiente, de todos los ministerios afectados por temas específicos o por grupos de temas homogéneos a tratar.

La organización de estos grupos de trabajo de la SECE no está formalmente institucionalizada. Sus agendas de trabajo se basan en los proyectos de decisiones y acciones que se discuten en las instituciones comunitarias. Cuando las decisiones de la Comunidad afectan a varios departamentos, el jefe de grupo, a veces bajo su propia iniciativa, a veces bajo la iniciativa de representantes del ministerio principalmente afectado por razón de la materia, convoca una reunión de su grupo de trabajo en la SECE con el objetivo de intercambiar información, examinar los efectos y, en la medida de lo posible, alcanzar un acuerdo para la toma de decisiones. Su función es el seguimiento de las decisiones de los grupos de trabajo del Consejo de Ministros en Bruselas y acercar las posturas de los representantes para reducir sustancialmente la carga de trabajo de la Comisión Interministerial para Asuntos Económicos de la Comunidad Europea. Su funcionamiento adecuado supondría consolidar el nivel 4 ó 5 en la escala de coordinación.

La opinión de la Secretaría de Estado para las Comunidades Europeas a finales de los ochenta era que "la manera más apropiada (de coordinar) es el mantener la intervención a nivel de la fase del Consejo de Ministros, ya que una intervención en las reuniones de la Comisión exige un aumento en la maquinaria administrativa. Además, hay muchos casos que son de la exclusiva competencia de un departamento, y por lo tanto la coordinación no es necesaria" (Presidencia de Gobierno, 1987, anexo p. 1).

Según otros participantes en el proceso de coordinación de la política comunitaria, no hay justificación o argumento contra el comienzo del esfuerzo de coordinación en la fase previa en la que la Comisión prepara sus propuestas en base a consultas con los expertos nacionales (generalmente funcionarios). "Actualmente (finales de los ochenta) hay una falta de coordinación (a niveles primarios). Ha habido casos en los que varios funcionarios de distintos ministerios han presentado simultáneamente posiciones distintas, contradictorias o incompatibles en la Comisión" (Presidencia de Gobierno, 1987, anexo p. 10). La opinión de la SECE era por el contrario que "lo mejor y lo más fácil para empezar es el unificar criterios con respecto a los documentos finales (COM final) de la Comisión".

En los primeros años hubo algunos casos de competencia entre funcionarios de distintos ministerios, solicitando que su ministerio fuera considerado el único responsable para tratar con un tema. Sus solicitudes fueron presentadas en persona o por notificación que sucesivamente eliminaba la autoridad de los otros. El sistema de coordinación no evitaba que se plantearan conflictos ante los gabinetes de los Comisarios españoles. Esto significaba que en aquellos años había dificultades para consolidar plenamente el nivel núm. 1 de la escala de coordinación. En la actualidad este nivel está consolidado, conociéndose con exactitud los grupos y los responsables de cada grupo, para lo cual se ha elaborado y difundido una lista a tal efecto.

Existen al menos tres razones que pueden explicar la situación inicial (a finales de los ochenta) de debilidad de coordinación. En primer lugar, de acuerdo con un funcionario superior trabajando en la Secretaría de Estado antes y después de la integración: "la adhesión provocó que muchos funcionarios que negociaron la adhesión dejaran la Secretaría de Estado para trabajar en otros centros. Algunos de ellos consiguieron puestos en las instituciones comunitarias, otros volvieron a los departamentos de origen, algunos fueron a la Representación Permanente y otros, incluso, se fueron al sector privado. Esta situación hizo necesario el que se reforzaran los recursos humanos de la Secretaría de Estado en alrededor de un 60 por 100 de aumento con personal altamente cualificado procedente de los distintos 
ministerios" (FERNÁNDEZ Prta, 1987, p. 68). Esto de hecho significó que, tras la adhesión, la mayoría de personal de la Secretaría de Estado (SECE), aunque perfectamente cualificados desde el punto de vista técnico, eran nuevos y no tenían experiencia previa en los procesos de coordinación de las negociaciones comunitarias. La gran ventaja de esta decisión era el facilitar la comunicación entre los ministerios sectoriales y la SECE, donde estaban permanentemente representados por personal procedente del mismo ministerio. Esta característica de la composición de la SECE, similar a la británica, ha facilitado el desarrollo de los niveles voluntarios de coordinación (del 1 al 5).

En segundo lugar, de acuerdo con las opiniones expresadas por los funcionarios entrevistados en otros ministerios, el problema de la SECE era una cuestión de no disponer de suficientes recursos y de redefinir su rol. Aunque los funcionarios de la SECE exigen una amplia información sobre todos los dossiers, no pueden, de hecho, tratar con todas las materias. Para alcanzar esto sería necesario replicar las unidades y duplicar el personal que trata los temas comunitarios en los ministerios gestores, reproduciendo el mismo trabajo en la Secretaría de Estado para las Comunidades Europeas. La SECE no puede trabajar a niveles de detalle administrativo. Podría coordinar con una perspectiva más estratégica o política y con una proyección a largo plazo. La SECE debería de disponer de una unidad de alta coordinación, un foro de reflexión sobre análisis sectoriales y globales. Esto permitiría consolidar los niveles superiores de la escala de coordinación.

El proceso de coordinación garantizado por la SECE cubre en muchas ocasiones las formalidades exigidas oficialmente, pero, de hecho, generalmente no se han llevado a cabo análisis o debates con una perspectiva global intra e intersectorial para planificar o diseñar una estrategia española respecto a Europa. La Secretaría de Estado está sobrecargada con su papel de guardián de los procesos formales de coordinación administrativa.

A finales de los ochenta el sistema de coordinación estaba claramente en vías de desarrollo y se enfrentaba con ciertas dificultades. El nivel jerárquico de la SECE no es siempre lo suficientemente alto como para imponer su postura en el alcance de la integración interdepartamental. Esta puede ser otra razón que explique su debilidad de coordinación en los primeros años. "Los Ministros sólo asisten al Consejo de Ministros y a las reuniones de la Comisión Delegada. En estos órganos, el nivel inferior de la Secretaría de Estado para las Comunidades Europeas obstaculiza su papel de mediador". Las sugerencias de localizar la unidad central de coordinación en la oficina del primer ministro siguiendo el modelo francés han sido ya expresadas (Mangas Martín, 1986 a, pp. 199 a 201, referencia en MAYOR, 1987, p. 14).

Desde principios de los noventa, de acuerdo con la opinión de funcionarios de la SECE, los sistemas de coordinación están mejorando, el reparto de competencias está claramente delimitado y los procedimientos estandarizados de coordinación están empezando a ser bien conocidos y aceptados por todos los participantes.

3.2.2 La Comisión Interministerial para Asuntos Económicos relacionados con las Comunidades Europeas (CIAECE).

Esta Comisión fue creada en septiembre de 1985 para ${ }^{2}$ :

a) coordinar la acción de la Administración respecto a temas económicos relacionados con la $\mathrm{CE}$;

b) informar sobre las decisiones tomadas por los ministerios sobre temas comunitarios que sólo pertenecen a su jurisdicción;

c) examinar y resolver temas que afectan a más de un ministerio pero que no requieren ser elevados a instancias de decisión superior;

d) elevar los temas de relevancia política o de interés para cualquier miembro a la Comisión Delegada (CDGAE).

El Presidente de la Comisión Interministerial es el Secretario de Estado para las Comunidades Europeas. Uno de los dos vicepresidentes permite una representación del Ministerio de Economía y Hacienda a alto nivel. La otra vicepresidencia es ocupada por la Secretaría de Estado para las Comunidades Europeas. Otros miembros de la Comisión Interministerial son los Subsecretarios del Ministerio de Agricultura, Industria, Trabajo, Seguridad Social y los Secretarios Generales de Hacienda, Comercio y Pesca. El director del gabinete del Presidente de Gobierno es también miembro de esta Comisión. Todos ellos pueden delegar la participación, pero no por debajo del nivel de director general.

La Comisión Interministerial se reúne aproximadamente cada tres semanas. El orden del día se compone de las siguientes partes: una primera parte en que se examinan y comentan los puntos incluidos en el orden del día de las próximas sesiones ministeriales del Consejo a celebrar; una segunda parte, relativa a "temas de información y discusión", de contenido muy variable, en que se debaten, en particular, los grandes temas de actualidad en el ámbito de la Unión Europea; y una parte final que incluye las actas de las sesiones ministeriales del Consejo que han tenido lugar desde la última reunión de la Comisión Interministerial.

La Comisión Interministerial generalmente trabaja más como una unidad de intercambio de opiniones, información y/o consulta con el fin de evitar divergencias (nivel 4 en la escala de coordinación). En ocasiones se resuelven conflictos pero en general su rol más usual es el intercambio de información entre las posiciones de los distintos ministerios. La Comisión Interministerial trata generalmente de temas específicos y con una perspectiva a corto plazo. No suelen llevarse a cabo debates estratégicos, comprensivos y a largo plazo. 
Las decisiones tomadas en la Comisión Interministerial son el resultado de negociaciones y consenso más que de un proceso de votación y/o arbitraje. Si no se alcanza un acuerdo o si el tema es considerado políticamente relevante por cualquier miembro de la Comisión Interministerial, el dossier pasa a ser examinado y resuelto por la Comisión Delegada del Gobierno para Asuntos Económicos, como veremos posteriormente.

Una vez las instrucciones son finalmente emitidas se envían a la Representación Permanente a través de la Secretaría de Estado para las Comunidades Europeas. Estas instrucciones son generalmente vinculantes a niveles de grupo de trabajo del Consejo, y a más alto nivel son dossiers más bien orientativos para los delegados españoles (Ministros o Secretarios de Estado) que proporcionan un marco y líneas generales de posiciones de negociación.

3.2.3 La Comisión Delegada del Gobierno para Asuntos Económicos.

Esta Comisión (CDGAE) tiene el poder directamente delegado del Consejo de Ministros para tratar de todos los temas económicos de relevancia política. Sus miembros son los Ministros de Economía y Hacienda, Industria, Trabajo y Seguridad Social, Agricultura y otros de naturaleza económica. Con el fin de que la Comisión Delegada pueda tratar adecuadamente los temas europeos, el Ministro de Asuntos Exteriores y el Secretario de Estado para las Comunidades Europeas son también miembros de la Comisión Delegada cuando ésta trate temas relacionados con las Comunidades Europeas ${ }^{3}$.

La Comisión Delegada discute y decide temas relacionados con las políticas europeas que le hayan sido elevados a su jurisdicción desde la Comisión Interministerial dada su relevancia política del tema o cuando alguno de los miembros de la Comisión Interministerial lo requiera. La Comisión Delegada es, casi siempre, el último resorte para los ministerios opuestos a cualquier decisión de la Comisión Interministerial.

Cuando haya una falta de acuerdo en la Comisión Delegada, los temas podrán terminar en el propio Consejo de Ministros, que tiene la última palabra. Sin embargo, "sólo las cuestiones de gran importancia, aquéllas con una verdadera dimensión políit$\mathrm{ca}$, tales como la política mediterránea, alcanzan el nivel de Consejo de Ministros. Los casos resueltos por la Comisión Delegada son también escasos" (MAYOR, 1987, p. 14).

\subsubsection{La Representación Permanente.}

La adhesión de España a las Comunidades Europeas también requirió el reforzamiento y potenciación de la Representación Permanente en Bruselas. Su estructura y responsabilidades fueron reajustadas para salvaguardar el principio de acción conjunta y conseguir una participación efectiva en la Comunidad Europea ${ }^{4}$.
La Representación Permanente tiene que ejecutar todas las instrucciones emitidas por el Gobierno y recibidas a través de la SECE. Es obligatorio para los funcionarios que se transmitan las comunicaciones entre la Representación Permanente y la Administración Española a través de los canales formales de la Secretaría de Estado 5 . Sin embargo, según las declaraciones de funcionarios superiores de la Representación Permanente y de los ministerios sectoriales, no todas las comunicaciones pueden ni necesitan ser formalizadas a través de la Secretaría de Estado. Es lógico que dada la necesidad de una toma de posiciones rápida en alguna de las negociaciones comunitarias, muchas consultas sean llevadas a cabo directamente por el delegado del ministerio correspondiente $y / o$ por el funcionario que se desplaza desde Madrid. Esto no implica que no haya un contacto directo y regular entre el representante de un Ministerio en la SECE con el personal de este Ministerio en sus actuaciones Europeas. La rapidez con que cambian las situaciones para muchos de los temas y procedimientos en los grupos de trabajo hacen muy difícil y quizá ineficiente el seguir al pie de la letra la reglamentación relativa al proceso de coordinación.

Según un artículo de la prensa diaria española (El País, 1987): "la falta de instrucciones o la transferencia de instrucciones contradictorias sobre un mismo tema por dos ministerios son (eran en 1987) casos usuales de la preparación de las negociaciones españolas en los grupos de trabajos comunitarios". "A veces un ministerio transmite (transmitía) simultáneamente el original de la instrucción a la Secretaría de Estado para las Comunidades Europeas y una copia a su delegado en la Representación Permanente. Después, si la SECE cambia (cambiaba) la instrucción, el delegado recibe (recibía) una nueva y diferente posición de negociación".

Sin embargo, en la actualidad, la tendencia de temas negociados en Bruselas con instrucciones de calidad desde Madrid es creciente.

Uno de los problemas de la Representación Permanente a finales de los ochenta era la dificultad o ausencia de una clara estructura. La definición de límites, responsabilidades y competencias no estaban bien definidas. Algunas áreas tenían contenidos solapados que no estaban claramente asignadas y distribuidas entre los diferentes ministerios. Aunque la departamentalización del funcionamiento de la Representación Permanente es paralela a la de la Administración en Madrid, la distribución era consecuencia de un desarrollo histórico más que de una lógica de funcionamiento. La distribución de grupos de trabajo a cada ministerio se basó, en un principio, en la distribución existente previa a la adhesión. En casos en los que la delimitación no era fácil, la participación de los delegados de dos o más ministerios era y puede ser conjunta. Como se dijo en la sección 3.2.1., en la actualidad se dispone de un listado con los responsables de cada grupo de trabajo. 
La principal función de la Representación Permanente es lógicamente el defender la posición española según instrucciones recibidas desde Madrid. Sin embargo, ésta también juega un papel significativo en la formulación de la postura española. Los delegados de la Representación Permanente en Bruselas pueden participar en la formulación de políticas y de hecho así lo hace viajando a Madrid para tomar parte en grupos de trabajo en la Secretaría de Estado para las Comunidades Europeas y en sus propios centros ministeriales para asesorar a los funcionarios superiores sobre los asuntos más importantes dentro de sus áreas correspondientes. Los delegados pueden en ocasiones preparar el borrador de lo que podríamos denominar una "autoinstrucción", enviarlo a Madrid y recibirlo de vuelta una vez que haya sido aprobado. Incluso la autoinstrucción en ocasiones se formula de tal manera que en caso de no haber contestación desde Madrid el silencio significaría acuerdo.

En general, los miembros de la Representación Permanente toman la iniciativa en la formulación de la postura española sobre temas que por su continuidad requieren la residencia en Bruselas. En algunos casos, el funcionario encargado negocia bajo su propia iniciativa sin que necesariamente existan instrucciones desde Madrid. Esto suele ocurrir cuando el delegado en Bruselas tiene una larga experiencia en el puesto y/o el funcionario responsable de estos temas en los ministerios sectoriales en Madrid tiene menos información y tiempo para elaborar su posición que el funcionario responsable en la Representación Permanente. Como un funcionario superior en un ministerio sectorial dijo: "si ellos (los delegados en Bruselas) me preguntan o me piden una decisión yo no tengo información suficiente ni tiempo para estudiar el caso y enviarle la instrucción de vuelta". Las negociaciones de otros temas que son tratados por los delegados que van y vienen desde Madrid a Bruselas no muestran esta característica. Los miembros de la Representación Permanente ayudan a los delegados procedentes de Madrid a establecer los primeros contactos y les apoyan en sus primeras reuniones.

Generalmente, para ganar tiempo se envía información y hay contacto directo entre los Delegados en la Representación Permanente y sus respectivos ministerios sectoriales. En muchas ocasiones, no sólo se envía información a la Secretaría de Estado para las Comunidades Europeas sino también una copia directamente al ministerio sectorial para evitar que "la información a veces llega (llegue) tarde" (MAYOR, 1987, p. 24).

Por lo que respecta a las negociaciones en el Consejo: "la delegación española en el COREPER está compuesta por personal de la Representación Permanente y funcionarios procedentes de Madrid. Los últimos tienen que ocuparse de los efectos especializados de la negociación que no pueden ser cubiertos por los primeros. Los expertos procedentes de Madrid no tienen una visión horizontal o global. Se concentran en los aspectos técnicos de sus dossiers y están relativamente menos al tanto de la situación en Bruselas. Estos disponen de una información e instrucciones más detalladas, definidas generalmente por los funcionarios superiores en Madrid, de tal manera que están limitados y sometidos a la capital y su capacidad de negociación es más limitada". La composición de estos grupos es similar a la del COREPER; el número de expertos procedentes de Madrid es mayor. Esto es particularmente más notable en el caso de los grupos de trabajo de agricultura. Al nivel de Consejo de Ministros la influencia de la Representación Permanente es obviamente más débil. Puede definir la agenda de cada Consejo y canaliza los intereses y las influencias de otros Estados miembros. Cada ministro negocia con el apoyo del representante permanente y varios consejeros para las cuestiones técnicas (MAYOR, 1987, pp. 27 y 28).

Los representantes españoles tienen que votar en ocasiones sin instrucciones escritas formales desde Madrid, pero de hecho tienen contactos directos y continuos con la SECE y los ministerios sectoriales. El sistema de transmisión de instrucciones parece ir consolidándose. Existe un número importante y creciente de negociaciones basadas en instrucciones previas.

3.2.5 El Departamento Internacional de la Presidencia de Gobierno.

El Departamento Internacional de Presidencia es otra unidad con influencia en la red del proceso de coordinación para la formulación de políticas comunitarias. Este departamento está representado en la Comisión Interministerial (CLAECE) por el director de su gabinete. Su principal función es garantizar la plena y continua información sobre la marcha de los temas europeos para el Presidente de Gobierno. Puede jugar un papel de gran influencia relativo a la formulación de las posiciones españolas en temas políticos específicos en los que el Presidente esté interesado. Pero el departamento de asuntos internacionales del gabinete del Presidente de Gobierno es esencialmente una unidad de seguimiento a distancia, mantiene al Presidente bien informado y preparado para mediar en caso de que sea necesario.

En ocasiones juega un papel importante como segundo nivel de control o reflexión. Por ejemplo, en abril de 1987, se mantuvo una reunión en la oficina del director del gabinete para tratar temas relativos a la selección de nacionales españoles para trabajar en las instituciones europeas y a la evaluación de la coordinación interministerial para la formulación de la políica europea. Esta reunión pudo suponer un punto de partida importante para el inicio de un proceso de desarrollo y mejora del sistema de coordinación. Análogamente, cada vez que España asume la Presidencia del Consejo de Ministros de la UE, el Comité Organizador de la Presidencia elabora un informe-evaluación sobre la gestión realizada (C. RuIz TARTAS, 1995, p. 4). 
"La Presidencia de Gobierno juega el papel de coordinación en la preparación de los Consejos de Europa" (MAYOR, 1987, p. 14). Su participación en los asuntos europeos se centra en el Consejo de Europa. En el marco del departamento de la Presidencia se ha creado el Comité Organizador de la Presidencia Española, encargado, entre otros temas, de la preparación de las principales reuniones de este evento semestral y del programa de formación de los funcionarios que participan como presidentes de grupo o como delegados españoles. El éxito organizativo y hasta cierto punto político ampliamente reconocido de las dos presidencias españolas (Enrique González Sánchez, 1989, p. 720; Carlota RUIZ TARTAS, 1995, p. 9) hace pensar en la consecución de altos niveles de coordinación cuando existe voluntad y liderazgo político para ello (nivel 8 de coordinación).

\subsubsection{La participación de las Comunidades Autónomas.}

La adhesión de España a las Comunidades Europeas ha coincidido con un importante proceso de descentralización tanto política como administrativa. La adhesión afecta no sólo al Gobierno central, reduciendo sus competencias, sino también a las de los nuevos Gobiernos autónomos. Desde un punto de vista constitucional, la Administración del Estado monopoliza las relaciones exteriores (artículo 149.1, párrafo 3 de la Constitución). Sin embargo, una interpretación estricta del concepto "relaciones exteriores" puede provocar serias redistribuciones y una vuelta atrás hacia una nueva centralización de unas competencias que acaban de cederse a las CC.AA. constitucionalmente. El conflicto no surge de una nueva demanda de los Gobiernos de las Comunidades Autónomas por las funciones clásicas de asuntos exteriores, tales como la representación oficial exterior, o las decisiones de alto nivel político (declaraciones de guerra o paz, reconocimiento de nuevos Estados, etc.). El problema se origina por la preocupación de las CC.AA. de depender del Estado, que al preparar una postura de negociación en Bruselas podría decidir sobre temas que, de acuerdo con la Constitución y los Estatutos de Autonomía, son también o sólo competencia de los Gobiernos regionales o autonómicos.

Hoy en día resulta cada vez más difícil separar los temas internacionales de los temas internos o domésticos. El comercio exterior, la pesca en alta mar, la emigración, el turismo, medio ambiente, etc., y otras actividades con perspectivas tanto externas como internas se han multiplicado. No parece razonable ni aconsejable interpretar rígidamente en su sentido amplio el término relaciones exteriores recogido en la Constitución, ya que el artículo 149 también especifica junto al concepto de relaciones exteriores otras competencias exclusivas del Estado tales como comercio exterior, política de aduanas, etc., como temas diferenciados. No obstante, hasta hace poco (1993) este problema no ha sido prioritario en la agenda de las CC.AA. "Las CC.AA. se han interesado principalmente en el planteamiento de conflictos de competencias en la fase de implantación del
Derecho Comunitario, y su representación, oficial o no, en Bruselas, no tanto así en la participación de la formación de la postura del Estado en temas europeos" (PÉrez Calvo, 1993, p. 251). Según el mismo autor, los Estatutos de Autonomía aluden a la participación en iniciativas europeas salvo excepciones aisladas a contenidos muy concretos, "totalmente alejados de las cuestiones europeas" (Pérez Calvo, 1993, p. 254). Varios Estatutos se refieren al derecho del Ejecutivo autonómico a ser informado en la elaboración de acuerdos internacionales que afecten a las Comunidades Autónomas. Pero nada se dice, salvo en el Estatuto Canario, a que se emita su parecer sobre la información recibida.

No obstante, con el fin de evitar una peligrosa vuelta atrás en un proceso de descentralización ya avanzado y simultáneamente asegurar la cooperación de los Gobiernos autonómicos en la implantación de la política europea, el Gobierno central ha aceptado la importancia de incorporar las Comunidades Autónomas y sus intereses en la fase de formulación de las politicas europeas. Desde un principio se reconoció que iba a ser necesario el que el Estado y las Comunidades Autónomas cooperaran de manera apropiada con el fin de resolver mediante acuerdos comunes los diversos temas que afectaban al interés nacional en Europa.

El primer proyecto de acuerdo político entre el Gobierno central y los Gobiernos autonómicos para su cooperación en temas europeos no fue aceptado. Los puntos más relevantes de este acuerdo se referían a la exclusividad en cuanto a representatividad del Gobierno central ante la Comunidad Europea. "Todas las comunicaciones con las instituciones comunitarias deberían ser materializadas a través del aparato del Estado para asuntos exteriores"; se hablaba de la buena fe en las relaciones y en el intento por parte del Gobierno central de incorporar los criterios y posiciones de las Comunidades Autónomas cuando quiera que fuera compatible con el interés general del Estado; y la obligación de que el Ministerio de Administraciones Públicas, mediante su Departamento de Administraciones Territoriales, debería enviar toda información europea relacionada con temas que puedan afectar a sus competencias. Con el fin de que las CC.AA. pudieran comentar y opinar sobre cualquiera de los temas, en este acuerdo se trataba ya como instrumento de participación de los Gobiernos autónomos las llamadas "comisiones mixtas" y cualquier otro órgano de cooperación cuando fuera necesaria. Este acuerdo fue rechazado por algunos Gobiernos autónomos por ser demasiado radical al dar el carácter de exclusivo a la representatividad del Gobierno central y no especificar órganos o instrumentos de representación por parte de las Comunidades Autónomas.

En un nuevo proyecto se sugerian dos instituciones específicas para permitir la participación de las Comunidades Autónomas durante la fase de formulación de la postura de negocia- 
ción española en Bruselas: en primer lugar, un "observador" elegido por los Gobiernos autónomos que serían nuevos delegados en la Representación Permanente para informar directamente y defender los intereses de las Comunidades Autónomas en Bruselas; en segundo lugar una Conferencia Sectorial para asuntos relacionados con las CC.EE. La Conferencia Sectorial ha supuesto un paso importante para la construcción de una opinión común entre ambos niveles de gobierno. La figura del observador aún no se ha materializado por falta de acuerdo sobre el número de observadores y la forma de reparto y/o rotación entre las CC.AA.

El funcionamiento de la Conferencia Sectorial para asuntos relacionados con las CC.EE. exigió su desglose en tantas Conferencias Sectoriales como políticas comunitarias en las que participarían el Ministro correspondiente y los Consejeros autonómicos de cada política concreta. La eficacia de las Conferencias Sectoriales es dispar, estando alguna de ellas en fase de buen funcionamiento (i.e. la Conferencia de Política Fiscal y Financiera) mientras que otras puede decirse que son todavía muy deficientes. El modelo de participación de las CC.AA. está evolucionando progresivamente mediante pasos a veces "informales" o naturales que luego van institucionalizándose de manera limitada y nunca definitiva (Enoch AlBERTi ROVIRA, 1994, pp. 591 y ss.).

Un ejemplo claro de esto es el hecho de que la mayoría de las Comunidades Autónomas dispongan de oficinas de representación que les permite ejercer una función de lobby y hasta cierto punto de representación, semi-oficial, ante la Comisión Europea.

Queda pendiente de desarrollo tanto la capacidad de "actuación mancomunada" que generalmente exige a las CC.AA. el acuerdo de 1994 para su participación (Enoch AlBerTi RovirA, 1994, p. 596) como la propia capacidad de coordinación interna de cada C.A.

\subsubsection{El Parlamento.}

La adhesión de España a la Comunidad Europea ha afectado a las competencias del Parlamento. Este ha perdido parcialmente su poder legislativo y de control del Gobierno. Hoy, está claro que la toma de decisiones de la política exterior está monopolizada por el Gobierno. En opinión del profesor Remiro Brotons, ambos, el Congreso y el Senado no participan "en el establecimiento de posiciones del Estado dentro de las organizaciones internacionales que toman decisiones que son obligatorias para sus miembros..." (REMiRo, 1985, p. 82). Las comisiones de asuntos exteriores del Parlamento no pueden ser consideradas como otra cosa sino especiales testigos de la política exterior, ya que no participan en su formulación ni controlan eficazmente su ejecución (REmiRo, 1985, p. 69).

Aunque existe una queja contra la intervención parlamentaria en la formulación de política exterior por su lentitud en la toma de decisiones, el Parlamento español ha reconsiderado su papel en la formulación de políica europea con el fin de participar en mayor medida en la formulación de la posición española en el Consejo de Ministros europeo y para la constitución de relaciones más fuertes con los parlamentarios europeos. Esto es especialmente así después de la firma del Tratado de Maastricht. La fórmula finalmente elegida por el Parlamento español para el seguimiento de los temas europeos ha sido la creación de una Comisión Mixta Congreso/Senado para tratar los temas relacionados con la Unión Europea. Este seguimiento se centra fundamentalmente en el control político de las competencias transferidas a la U.E. Ante esta Comisión suelen rendir cuentas e informar los Ministros y el Secretario de Estado para la Comunidad Europea.

\subsubsection{La Coordinación intradepartamental.}

En general, la responsabilidad por la coordinación interna de cada ministerio resta en las Secretarías Generales Técnicas. Estos centros están encargados de la comunicación y distribución de la información dentro del departamento. En cada ministerio existe una red adecuada a los temas europeos y tratados por los centros interesados. Dada la gran variedad de departamentos nos centraremos tan sólo en uno de ellos. Veamos, por ejemplo, la adaptación del Ministerio de Economía y Finanzas a las negociaciones en Bruselas y más específicamente en el caso del presupuesto comunitario.

El Ministerio de Economía y Hacienda está compuesto por la Secretaría de Estado de Hacienda y la Secretaría de Estado de Economía, ambas pesos pesados en los temas europeos. La Secretaría de Estado de Hacienda trata temas que directa o indirectamente afectan al Fondo de Desarrollo Regional, Fondo de Cohesión, etc., y a la participación espanola en el presupuesto comunitario, en aduanas, en impuestos, etc., y la Secretaría de Estado para Economía trata con temas relacionados con la politica monetaria, la planificación económica. Por lo tanto, la participación del Ministerio de Economía y Hacienda en los asuntos europeos y el número de sus funcionarios y divisiones afectadas es importante.

En opinión de un alto funcionario del Ministerio de Economía y Hacienda, la Secretaría General Técnica debería coordinar horizontalmente a las Direcciones Generales y a sus servicios, pero no debería de asumir directamente papeles sustantivos. "Coordinar sí, sustituir no". Hoy la Secretaría General Técnica de Hacienda recibe información de la Representación Permanente a través de la Secretaría de Estado para las Comunidades Europeas y en ocasiones envía instrucciones relativas a temas de aduanas y de presupuestos.

Desde finales de los ochenta se aprecia una clara mejoría en la unificación de la postura y voz de este ministerio y más específicamente en la Secretaría de Estado de Hacienda, en las nego- 
ciaciones europeas y en la participación en los centros de coordinación.

Centrémonos en uno de los temas más importantes de la Secretaría de Estado de Hacienda, el presupuesto comunitario. Para coordinar la posición española relativa con el presupuesto comunitario, se creó la Subdirección de Presupuesto Comunitario. Una de las principales prioridades de la Subdirección de Presupuesto Comunitario es defender un sistema de financiación del presupuesto lo más progresivo posible, de manera que se maximice la aportación relativa de los países menos prósperos. Realiza un seguimiento de los flujos financieros y también realiza simulaciones sobre sistemas alternativos de financiación del presupuesto comunitario. El objetivo ha sido el maximizar las transferencias de los fondos estructurales y de cohesión con vistas a obtener un saldo neto lo más favorable a España y correspondiente a su nivel de desarrollo. Esto ha tenido una clara relevancia política. Este tema aparece de una manera asidua en la prensa y las presiones al Gobierno de los grupos empresariales han sido considerables.

En la SEH se han realizado estudios con proyección futura sobre el presupuesto comunitario. Se estiman escenarios macroeconómicos sobre efectos financieros a medio plazo de distintas decisiones sobre las finanzas comunitarias. Diversas vías de financiación tales como los programas integrados mediterráneos, etc., no han sido plenamente aprovechadas en el pasado.

En los primeros años de España en la CE, las reuniones internas de Presupuestos con los centros gestores no eran sistemáticas sino ad boc. Los delegados de los grupos de trabajo no obtenían instrucciones. Como uno de los entrevistados expresó: "si los delegados disponen de instrucciones, éstas vienen directamente de las direcciones generales". Por lo tanto, si hay instrucciones, éstas son fragmentadas y con perspectiva sectorial. Otro funcionario comentó: "cuando se negocian los artículos presupuestarios no tenemos una perspectiva comprensiva. Ya que no disponemos de información sobre las prioridades de otros ministerios no podemos negociar de manera complementaria en las concesiones con otros países".

Para resolver estos problemas, en la Secretaría de Estado de Hacienda se creó, como se ha anticipado, la Subdirección General de Presupuesto Comunitario. Uno de los papeles de esta subdirección es el recoger la información de los distintos ministerios sobre sus prioridades con respecto a la propuesta de presupuesto de la Comisión. Aunque esta información fue solicitada por escrito en 1986 para el presupuesto de 1987 la situación no varió ese año. Los ministerios contestaron sin cuantificar ni ordenar sus intereses prioritarios. Posteriormente el sistema ha ido mejorando.

Actualmente (ver figura de la página siguiente) dos unidades se reparten el trabajo de coordinación de los distintos intereses: uno interno al ministerio (la propia Subdirección de Presupues- to Comunitario) y otro externo (los grupos de fondos). La Subdirección de Presupuesto Comunitario, además de ser responsable de la recogida de toda información financiera, analiza las previsiones de ingresos y gastos presupuestarios de la Comunidad que afectan a España. Las reuniones del grupo de fondos permite la consulta y contactos directos entre los distintos ministerios que participan en los fondos estructurales del FEOGA orientación por el MAPA, el Fondo Social por el MTSS, y el FEDER y los Fondos de Cohesión por la Dirección General de Planificación de la Secretaría de Estado de Hacienda que canaliza los intereses de las Comunidades Autónomas en lo que les afecta este tema. Otros flujos financieros provenientes de la $\mathrm{CE}$, tales como las transferencias del FEOGA-Garantía se registran en el presupuesto de ingresos del FORPPA (actualmente FEGA, Fondo Español de Garantía Agraria) (Secretaría de Estado de Hacienda, 1995, p. 75).

Estos grupos de fondos están compuestos por los responsables de los servicios administrativos de los fondos implicados y los responsables de la Secretaría de Estado de Hacienda con respecto a la gestión presupuestaria comunitaria. Los temas y las discusiones desarrolladas en estos grupos de fondos y en la Subdirección de Presupuesto Comunitario sirven principalmente para elaborar los presupuestos de ingresos del Estado español.

El sistema de coordinación dentro del Ministerio de Hacien$\mathrm{da}$, con vistas específicamente a la formulación del presupuesto comunitario, ha mejorado de forma evidente durante los últimos años. El proceso de integración de los distintos intereses ha comenzado a consolidarse gracias a la Subdirección General de Presupuesto Comunitario de la SEH y a la Subdirección General de Coordinación Comunitaria para Asuntos Económicos en la SECE, que mantiene reuniones interdepartamentales con los centros gestores. Estas Subdirecciones garantizan que se recoja la información disponible o presentada de los distintos ministerios y centros gestores de manera escrita y, además, a través de contactos directos con los distintos responsables de los proyectos o partidas de crédito. Se está pasando de una situación que en los primeros años podría calificarse a un nivel 2 ó 3 en la escala de coordinación con vistas a consolidar el intercambio de información escrita, o comunicada por otro medio, a la consolidación de los niveles 4 y 5 en los que los distintos centros interesados se ponen en contacto directo y personal con vistas a mejorar la capacidad de identificar e integrar problemas y/o intereses comunes. El funcionamiento de los mecanismos de arbitraje y solución de conflictos (nivel 6) están garantizados por la vía jerárquica interna de Ministerio de Hacienda y/o externa a través de los órganos centrales de coordinación general: la CIAECE y la CDGAE. Incluso está extensamente difundida y conocida la postura/instrucción general de no aceptar propuestas, cualquiera que sea el grupo de trabajo, que signifiquen una reducción de la participación española en los fondos de cohesión (nivel 7 de coordinación). En consonancia con esta postura, los proyectos 


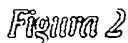

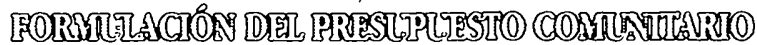

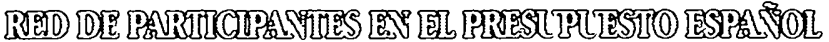

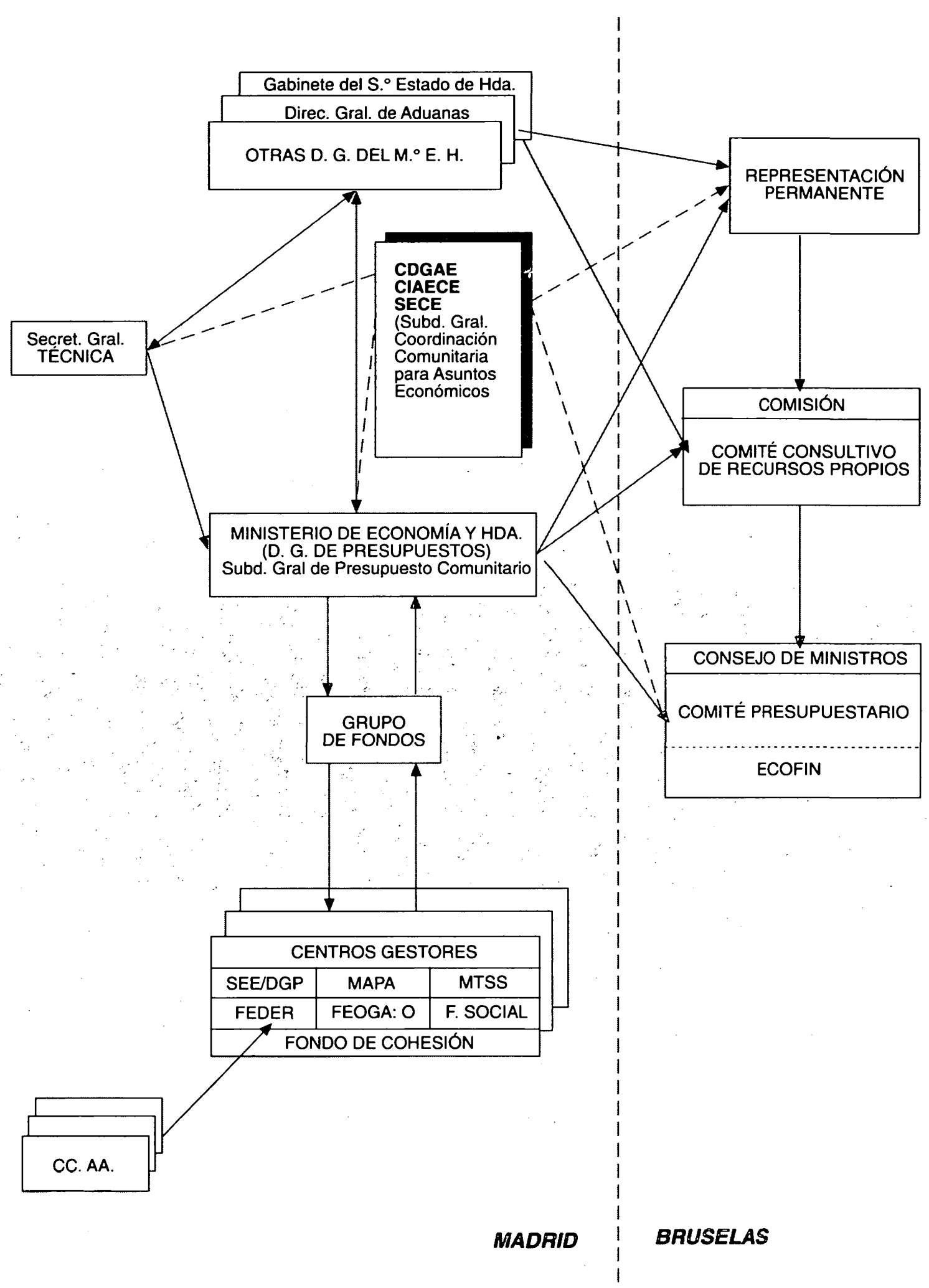


de inversión cofinanciados por la UE han tenido prioridad no sufriendo el recorte presupuestario generalizado en la elaboración de los presupuestos generales de este 1996.

Es importante tener en cuenta que si la política agrícola comunitaria disminuye en peso relativo en favor a los fondos estructurales, como parece orientarse la tendencia del presupuesto comunitario, entonces será necesario el desarrollo de la capacidad de gestión tanto a nivel central como a nivel autonómico para permitir la presentación no sólo de un mayor número de proyectos sino de proyectos de mayor calidad y relevancia y mejorar la capacidad para poder llevarlos a cabo con eficacia posteriormente. Sin tales mejoras será imposible aprovechar las posibilidades ofrecidas por los recursos procedentes de la Comunidad Europea. El aumento del número de proyectos a presentarse en los fondos estructurales y de cohesión exige el desarrollo específico de la capacidad de su gestión tanto operativa como estratégica, de los centros beneficiarios de las ayudas europeas.

La aprobación de cualquier normativa que suponga un aumento de gasto conlleva un estudio y estimación de la dotación presupuestaria previsible. Esto quiere decir que el proceso de elaboración del presupuesto es continuado, durante todo el año. Cada vez que se discute una Directiva se están teniendo en cuenta los efectos presupuestarios de la misma. Posteriormente, la elaboración del presupuesto supone, generalmente, el cálculo definitivo de las variaciones debidas a nueva normativa o acuerdos previos del Consejo de ampliación de partidas existentes. El anteproyecto de presupuesto se presenta al final del primer semestre, enviándose, para su lectura en el Parlamento. Tras cumplir las condiciones del proceso de codecisión se aprueba finalmente por el Consejo de Ministros a finales de diciembre.

La Subdirección General de Coordinación Comunitaria para Asuntos Económicos en la SECE mantiene reuniones interdepartamentales con los centros gestores.

\section{Evaluación de la adaptación de la Administración española}

De acuerdo con el resultado de las entrevistas y los documentos consultados existen evidencias de que el nivel de coordinación o la capacidad de coordinación sufrió una caída importante inmediatamente después de la adhesión de España a la Comunidad. Antes de la adhesión el sistema de coordinación funcionaba bien y era suficientemente efectivo como para llevar de una manera flexible y rápida la coordinación para la nego- ciación con la Comunidad Europea. Los problemas de coordinación después de la adhesión eran diferentes y más complejos. La coordinación previa a la adhesión se llevaba a cabo por un grupo pequeño de funcionarios (task force) que realizaba negociaciones bilaterales con la Comunidad Europea. Después de la adhesión la Secretaría de Estado para las Comunidades Europeas comenzó a desarrollar un sistema más apropiado para mantener relaciones con los distintos ministerios y gestionar un proceso continuado y más complejo de negociaciones multilaterales. Existen cuatro razones que explican la caída en la eficacia de coordinación del sistema inmediatamente después de la adhesión a la Comunidad:

1. Las negociaciones pasaban de ser bilaterales a multilaterales.

2. No existía ya una clara prioridad generalmente aceptada (tan indiscutible como era la propia adhesión en el proceso previo).

3. El grado de apoyo e interés de la Presidencia de Gobierno se centró en los problemas de relevancia o sensibilidad política.

4. Los funcionarios superiores que trabajaron en el proceso de adhesión se trasladaron de la SECE a otros puestos de trabajo en Bruselas, a sus propios Ministerios o a la empresa privada. Los nuevos funcionarios, aunque de alta competencia profesional, no todos tenían experiencia previa en temas comunitarios.

Por estas razones, y dado que el modelo de coordinación oficialmente elegido era muy largo y centralizado, el sistema funcionó con un nivel bajo de coordinación (ver figura 3) y tardó varios años en evolucionar. En los primeros años, tras la adhesión, el nivel de coordinación no alcanzaba el nivel percibido como necesario y las expectativas previstas por ley. A menudo los ministerios actuaban de manera independiente. Existía un contacto directo entre los delegados de la Representación Permanente y cada ministerio sin que se realizase con eficacia una función de coordinación global desde la SECE. Las instrucciones en algunos casos eran contradictorias y/o enviadas por distintos ministerios sobre un mismo tema. En otras ocasiones, las instrucciones se transmitían a la Secretaría de Estado para las Comunidades Europeas y simultáneamente al delegado en la Representación Permanente. A veces, la Secretaría de Estado para las Comunidades Europeas cambiaba estas instrucciones de tal manera que el delegado recibía dos instrucciones diferentes.

No se desarrollaban estrategias a medio o largo plazo con prioridades que orientaran de manera positiva la toma de posturas de negociación en Bruselas. La Comisión Interministerial funcionaba generalmente como un centro para compartir información más que un foro para el debate en profundidad de alternativas sobre temas de importancia. De hecho, se la 
calificaba como una institución para la legitimación de las instrucciones que eran enviadas a la Representación Permanente. El funcionamiento del nivel 6 de arbitraje estaba previsto que se realizase en la CDGAE, pero el número de conflictos era muy reducido. Apenas habian transcurrido tres años tras la adhesión, por lo tanto, no era sorprendente que el modelo estuviera en fase de desarrollo y consolidación de los niveles inferiores de la escala. De acuerdo con la información y datos recogidos sobre la situación a finales de los ochenta, el modelo español se situaba en la escala entre los niveles 4 (evitando divergencias) y el nivel 3 (consulta interministerial) como representativos de la capacidad de coordinación del sistema. Pero el sistema de coordinación estaba indicando un nuevo proceso de aprendizaje y transformación. Los grupos de trabajo en la Secretaría de Estado juegan un papel importante de coordinación. Su principal tarea es el facilitar el intercambio de información a nivel de los grupos de trabajo del Consejo de Ministros con el fin de evitar posiciones incompatibles. La toma de posición ante Europa en general era más reactiva que pro-activa (nivel 3 ó 4) realizando el esfuerzo de coordinación una vez elaborado el COM-Final.

En los últimos años, de la 1.? (1. ${ }^{\text {e }}$ semestre de 1989) a la $2 .^{.}$ presidencia ( $2 .^{\circ}$ semestre de 1995$)$, el sistema de coordinación ha ido consolidando niveles superiores en la escala. Dadas las características y la evolución del modelo español parece que existe una mejoría general del proceso de coordinación de la SECE, centralizando y garantizando un buen funcionamiento del proceso de instrucciones. Ya sea por mecanismos formales escritos o por contactos informales pero regulares y continuos, los cinco primeros niveles de coordinación están consolidados. El sistema también tiene capacidad para funcionar al nivel 6 de coordinación tanto a nivel intradepartamental (i.e. Ministerio de Hacienda) como interministerial (CDGAE).

La información recogida muestra evidentes mejoras que permiten pensar en que se están cubriendo los vacíos existentes entre los niveles oficialmente declarados y los que realmente están en funcionamiento. Los niveles 3, 4 y 5 de la escala de coordinación (compartir información para la búsqueda de intereses comunes) pueden considerarse consolidados:

1. La comunicación y capacidad de integración a nivel intraministerial ha mejorado (por ejemplo, la Dirección General de Presupuestos ha establecido una red de enlaces con centro en la Subdirección General de Presupuestos, el grupo de fondos, etc.). Esto facilita la gestión interna de las relaciones interministeriales.

2. Se han incorporado más recursos (nuevas tecnologías, personal).

3. El número y calidad de las instrucciones ha aumentado.

4. La representación en la Comisión Interministerial es más regular y estable
5. Los Gobiernos autónomos y el Gobierno central han acordado salir de la situación de tablas en la que se encontraban. Su participación es parecida a la alemana basada en conferencias sectoriales.

6. Aunque, puntualmente, el gabinete de la Presidencia realizó en ocasiones funciones de evaluación del propio sistema de coordinación.

7. Las relaciones entre la SECE y los departamentos ministeriales están bien garantizadas gracias a la representación estable de éstos en la SECE. El contacto continuo, diario si fuera necesario, entre compañeros del mismo ministerio o incluso del mismo cuerpo, asegura una comunicación en tiempo real.

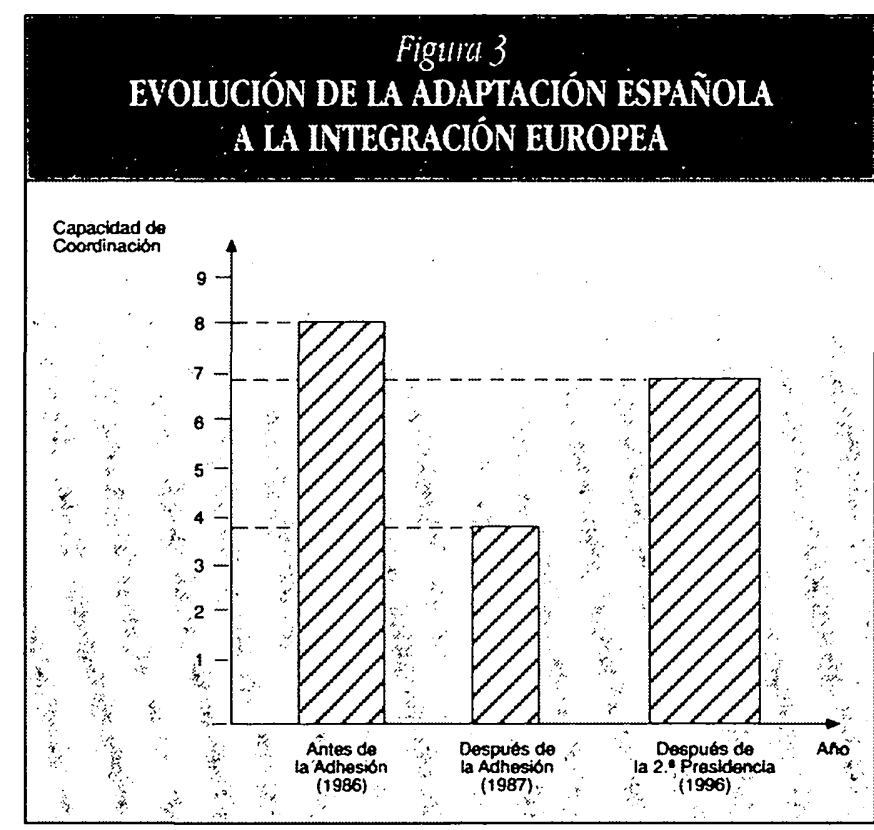

\section{Conclusión: un sistema de coordinación en claro proceso de evolución}

En conclusión, el sistema se ha desarrollado hacia un modelo centralizado (nivel 6). Incluso podría hablarse de alcanzarse el nivel 7 (parámetros de negociación) de coordinación si se tiene en cuenta la actitud general de los negociadores españoles respecto al mantenimiento y mejor aprovechamiento de los fondos de cohesión. Los niveles inferiores con elementos básicos de coordinación (la consulta, la información, el evitar divergencias, etc.) pueden considerarse consolidados. Cabrían aún mejores si se prestara una mayor atención al proceso de coordinación vertical de arriba abajo como ocurre durante los períodos 
de presidencia espanola $(1989,1995)$ donde se puede decir que el nivel de coordinación alcanza el nivel 8 . También puede sugerirse la creación de una unidad de análisis con recursos propios y personal permanente para la reflexión estratégica continuada. La SECE no puede trabajar a niveles de detalle administrativo. Podría coordinar con una perspectiva más estratégica o política y con una proyección a largo plazo. La SECE debería disponer de una unidad de alta coordinación, un fórum de reflexión sobre análisis sectoriales y globales. Esto permitiría consolidar los niveles superiores de la escala de coordinación.

En el momento de escribir estas líneas España termina su papel de Presidencia del Consejo de Ministros por segunda vez. El esfuerzo hecho de reasignación de recursos humanos por la Administración española y los programas de formación e información llevados a cabc para la preparación de la primera Presidencia de la multitud de grupos de trabajo en el Consejo de Ministros permitió sin duda aumentar su capacidad de coordinación, habiendo consolidado muy probablemente los niveles que en los últimos años había ya iniciado. De nuevo, el proceso de mejora es evidente: preparación de un mayor número de funcionarios (cursos de formación en colaboración con el Instituto Europeo de Administración Pública) la incorporación de expertos de la carrera diplomática recientemente retirados (i.e. Raimundo Bassols) como asesores y los altos niveles de informatización de las comunicaciones así como la elección de prioridades:

- el relanzamiento económico de Europa en un marco social integrado

- una Europa abierta a los ciudadanos

- fijación de las bases para la Europa del futuro: conferencia intergubernamental de 1996.

Tras el fin del período presidencial español es de esperar que los niveles de coordinación y la capacidad del aparato administrativo para integrar sus distintos intereses se estabilice y consolide. De hecho, ya en los últimos meses de la presidencia española, está siendo reconocido casi unánimemente el éxito organizativo de la misma. No obstante, los nuevos retos que se presentan en Europa (unión económico monetaria, conferencia intergubernamental de 1996, etc.) exigirán un mayor desarrollo de la capacidad de coordinación de todos los países de la Unión Europea. La adaptación de la Administración para la formulación de la política europea no puede ser vista simplemente como un esfuerzo aislado, sino como un proceso de aprendizaje continuo en respuesta a cambios o nuevos retos en el entorno (ampliación, profundización, etc.). En la medida que nuevos desafíos vayan apareciendo será necesario desarrollar nuevas capacidades de distinto grado y de distinta naturaleza para iniciar nuevos procesos o curvas de aprendizaje organizacional (ver figura 4).

El sistema de trabajo se basa en los llamados Com finals, es decir, los documentos de la Comisión enviados al Consejo de Ministros de la Comunidad Europea, que son distribuidos en la Comisión Interministerial cada semana. Los ministerios afectados presentarán sus posiciones sobre el Com finals y, cuando lo consideren necesario, se enviarán las instrucciones a la Representación Permanente.

La capacidad de persuasión de los funcionarios responsables de los temas comunitarios en Madrid, el concepto de nueva identidad o sobre las tareas a jugar por la Secretaría de Estado para las Comunidades Europeas y la de peso político personal del Secretario de Estado para las Comunidades Europeas, todos ellos son factores de gran importancia para la eficacia de su trabajo.

Una de las evidencias más válidas del buen funcionamiento de un sistema de coordinación es la existencia y calidad de las instrucciones que reciben los delegados nacionales al entablar las negociaciones regionales. La calidad de las instrucciones se refleja en las siguientes características (Enrique GonZÁLEZ SÁnchez, 1991): unicidad, oportunidad, claridad y flexibilidad.

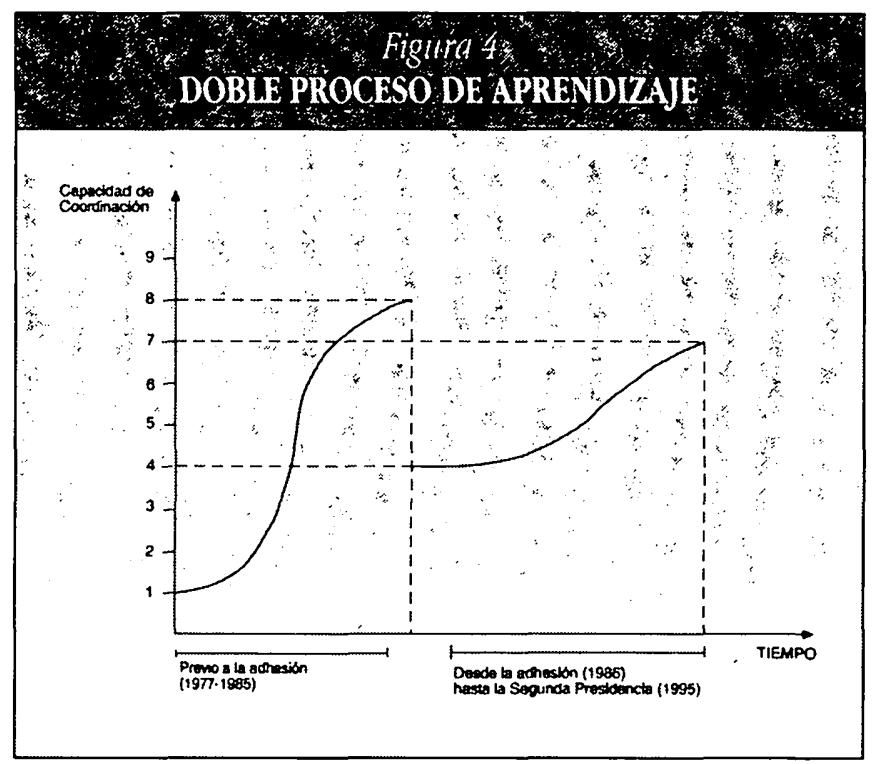

* Asesor del Instituto de Estudios Fiscales.

1 Ministerio de Asuntos Exteriores (SECE), Las negociaciones para la adbesion de España a las CCEE, pp. 9 y ss., Consejo Superior de Cámaras de Comercio, Madrid, 1985.
${ }^{2}$ Real Decreto 629/1983, de 16 de febrero.

${ }^{3}$ Idem, p. 10.

4 Real Decreto 1267/1983, de 11 de mayo.

' Real Decreto 1567/1985, de 2 de septiembre. 
ALBERTí Rovira, Enoch, (1994), "El modelo español de participación de las Comunidades Autónomas en los Asuntos Europeos (Comentario al Acuerdo de 30 de noviembre de 1994, de la Conferencia para Asuntos Relacionados con las Comunidades Europeas)", en Eliseo Aja (Director), Informe Comunidades Autónomas, ed. Instituto de Derecho Público, 1995.

Bass, Marin, (1985), Derecbo Comunitario y Derecbo Administrativo, Publicación para el Mundo del Derecho, diciembre.

CAMBIO 16, 5 marzo 1987.

COMSIÓn EUROPEA, (1994), On tbe Development of Administrative Cooperation in the Implementation and Enforcement of Community Legislation in the Internal Market, $\operatorname{COM}(94) 29$ final, Bruselas.

EL Pais, 10 mayo 1987.

Ferníndez Pita, Rafael, (1987), "La Adhesión de España a las Comunidades Europeas: aspectos organizativos", en: Revista de Estudios e Investigación de las CCEE. Ed. Dcho. Reunidas, Madrid, No. 1, Madrid.

FTrt MaUrice, John, (1983), "European Community Decision-Making: The National Dimension", en: J. Lodge, (ed.), Institutions and Policies of the European Community, Pinter, London.

Gabinete del Vicepresidente Español en la Comisión Europea, (1987), Informe sobre el Funcionamiento de la Administración Española con respecto a las Instituciones Comunitarias, no publicado, mayo.

González Gallarza, R., (1985), "Preparation des carrières communautaires" en: W. WESSELS, J. JAMARED, L'Administration communautaire a l'beure du choix, De Tempel, Bruges.

Gonzilez Sánchez, Enrique, (1984), "Participación de España en las instituciones comunitarias y en los mecanismos de la cooperación política", Documentaciōn Administrativa, No. 201, julio-septiembre.

- (1984), "Participación de España en las IICC, el Proceso de Decisión Comunitaria", Documentación Administrativa, No. 21, julio.

- (1989), "La Presidencia Española de la Comunidad Europea", Revista de Instituciones Europeas, pp. 691-723.

Hine, Robert C., 1989, "Customs Union Enlargement and Adjustment: Spain's Accession to the European Community", Joumal of Common Market Studies, Volume XXVIII, n. ${ }^{\circledR}$ 1, septiembre 1989, pp. 1-27.

KLIKSBERG, Bernardo, (1994), "The 'Necessary State': a strategic agenda for discussion”, Intermational Review of Administrative Sciences, Vol. 60, N. 2 .

LEGuina, Joaquín, (1986), La Comunidad de Madrid, España y la CEE, Tapia, enero.

LEQUESNE, Christian, (1986), "Les instruments de la politique européenne de la France", Rapport de Recherche, DEA, IEP de París.

Mangas Martín, Araceli, (1986a), Derecho Comunitario europeo y Derecho espanol, Ed. Tecnos, Madrid.

- (1986b), El Comité de Representantes Permanentes de las Comunidades Europeas, Centro de Estudios Constitucionales, Madrid.

MAYOR LÓPEZ, Pedro, (1987), "Interministerial Coordination for the Formulation of the Spanish Position on Community Policies", Research in the College of Europe, Bruges, abril.

MESA, Roberto, (1985), "El Proceso de Toma de Decisiones en Política Exterior", Documentación Administrativa, No. 205, junio.

MetCalfE, Les, (1992), "After 1992: Can the Commission Manage Europe?", Australian Journal of Public Administration, 51 (1), march, 117-130.

- (1993), "Gerencia de los Procesos de Integración: Liderazgo, Gestión y Coordinación", en Integración latinoamericana, mayo-junio 1993, p. 10-18.
METCuff, Les, (1994), "International Policy Coordination and Public Management Reform", International Review of Administrative Sciences, SAGE, London, Vol. 60 p. 281.

MinaRD, Alan S., (1992), The European Rescue of the Nation-State, Routledge, London.

Ministerio de Economía y Hacienda, 1995, Relaciones financieras entre España y las Comunidades Europeas, Secretaria de Estado de Hacienda, Dirección General de Presupuestos, p. 75.

Ministerio de Asuntos Exteriores (SECE), (1985), Las Negociaciones para la Adbesión de España a las C.E., Consejo Superior de Cámaras de Comercio, Madrid.

MODERNE, Franck, LAdministration Espagnole et l'Intégration Européenne?

Nuallain, Colm, (ed.) en colaboracion con J-M. Eocchert, (1985), The Presidency of the European Council of Ministers: Impacts and Implications for National Governments, Croom Helm, London.

Oszlak, Oscar, 1995, Estados Capaces: un desafio de la Integración, artículo presentado en el Taller de Trabajo "Capacidades de Coordinación y Control II: Fortalecimiento de las Administraciones Públicas Nacionales para la Integra. ción Regional", organizado por el CEFIR en Montevideo, Uruguay, 18-20 abril 1995.

Pérez Calvo, Alberto, (1992-1993), "Participación de las Comunidades Autónomas en la formación de la posición que el Estado ha de trasladar a las instituciones comunitarias", D.A. n. 232-233, p. 252.

Pons Irazazabal, Félix, (1986), El Estado de las Autonomias ante la CE, Tapia, enero.

Presidencia de Gobierno, (1987), Informe sobre coordinación temas CEE, sin publicar. Abril.

Remiro Brotons, Antonio, (1985), "El Poder Exterior del Estado", Documentación Administrativa, No. 205, junio.

Ruz TARTAS, Carlota, 1995, La Présidence du Conseil de I'Union Eumopéenne et la deuxième Présidence espagnole, EIPA SCOPE, European Insitute of Public Administration, pp. 2-10.

SABA, Katlyn, 1985, "The Spanish Foreign Policy Decision-Making Process", en "Spain and Portugal and European Political Cooperation", dirigido por IAI y el Institut für Europäische Politik in Bonn.

SIEDENTOPF, Heinrich, y ZiluER, Jacques, (1988), Making European Policies Work, EIPA.

SмITH, P., (1993), Ed. The Challenge of Integration, North-South Center, Transaction, London, pp. 62 y 63.

TaRRadellas, Josep, (1985), Será la Europa de los Estados no de las Naciones, Publicación para el Mundo del Derecho, diciembre.

Villar OrTtz de Urbina, Francisco, (1985), "Diplomacia Multilateral y Servicio Exterior", Documentación Administrativa, No. 205, junio.

ViǸAs, Angel, (1985), "La Función de Planificación en Política Exterior", Documentación Administrativa, no. 25, junio.

WaLlaCE, Helen, (1983), "Negotiation, Conflict and Compromise: The Elusive Pursuit of Common Policies", en: Helen Wallace, William Wallace y Carol Webb, (eds), Policy-making in the European Community, J. Wiley, Second edition, London.

- (1983), National Governments and the European Communities, Chatham House, PEP Number 21, London.

WaLton, Richard E., y McKersie, Robert B., (1965), A Bebavioural Theory of Labour Negotiations, McGraw Hill, New York. 


\section{Novedad}



La presente obra incluye el texto actualizado del Código Civil, incorporando las últimas modificaciones introducidas por la Ley Orgánica 1/1996, de 15 de enero, de Protección Jurídica del Menor, de modificación parcial del Código Civil y de la Ley de Enjuiciamiento Civil, acompañado de once mil sentencias del Tribunal Supremo transcritas o referenciadas.

El libro está organizado de forma que sistematiza, ordena y entrelaza la jurisprudencia incluida, de manera que se facilite tanto su manejo como el conocimiento de las interrelaciones y conexiones de todo el entramado jurisprudencial y legislativo.

La edición se completa con dos índices: cronológico de todas las sentencias transcritas o referenciadas, con indicación de los números marginales en que se encuentran y una breve especificación de su contenido, y analítico del articulado del Código.

\section{1.² edición (enero de 1996), 2.336 páginas, 18.600 pesetas}

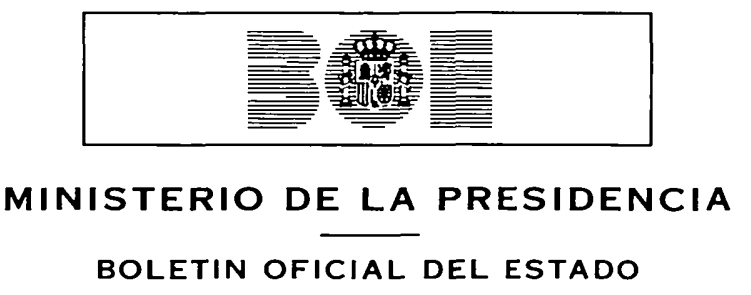

Trafalgar, 29. 28071 MADRID

Teléfonos: Centralita: 5382100 / Información: 5382290 Anuncios: 5382294 / Libreria: 5382295

Suscripciones: 5382297 